\title{
Correction to: The concept of disability and its causal mechanisms in older people over time from a theoretical perspective: a literature review
}

Ines Mouchaers ${ }^{1,2,3}$ (D) Hilde Verbeek ${ }^{1,2} \cdot$ Gertrudis I. J. M. Kempen ${ }^{1,2} \cdot$ Jolanda C. M. van Haastregt $^{1,2}$. Ellen Vlaeyen ${ }^{3}$ - Geert Goderis ${ }^{4}$. Silke F. Metzelthin ${ }^{1}$

Published online: 3 March 2022

(c) Springer Nature B.V. 2022

Correction to: European Journal of Ageing https://doi.org/10.1007/s10433-021-00668-w

In the original publication of the article, the Fig. 2 was incorrectly published.

The correct Fig. 2 is given below.

The original article has been corrected.

The original article can be found online at https://doi.org/10.1007/ s10433-021-00668-w.

Ines Mouchaers

i.mouchaers@maastrichtuniversity.nl

1 Department of Health Services Research, Faculty of Health Medicine and Life Sciences, CAPHRI Care and Public Health Research Institute, Maastricht University, P.O. Box 616, 6200 MD Maastricht, The Netherlands

2 Living Lab of Ageing and Long Term Care, Maastricht, The Netherlands

3 Department of Public Health and Primary Care, Academic Centre for Nursing and Midwifery, KU Leuven, Leuven, Belgium

4 Department of Public Health and Primary Care, Academic Centre for General Practice, KU Leuven, Leuven, Belgium 
a) Nagi's Disablement Model $(1965,1991)$

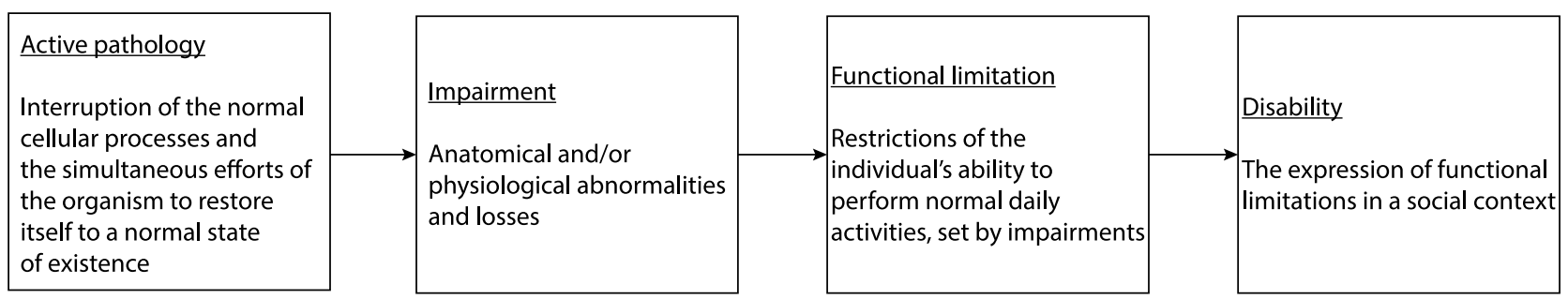

b) WHO's International Classification of Impairments, Disabilities, and Handicaps (1980)

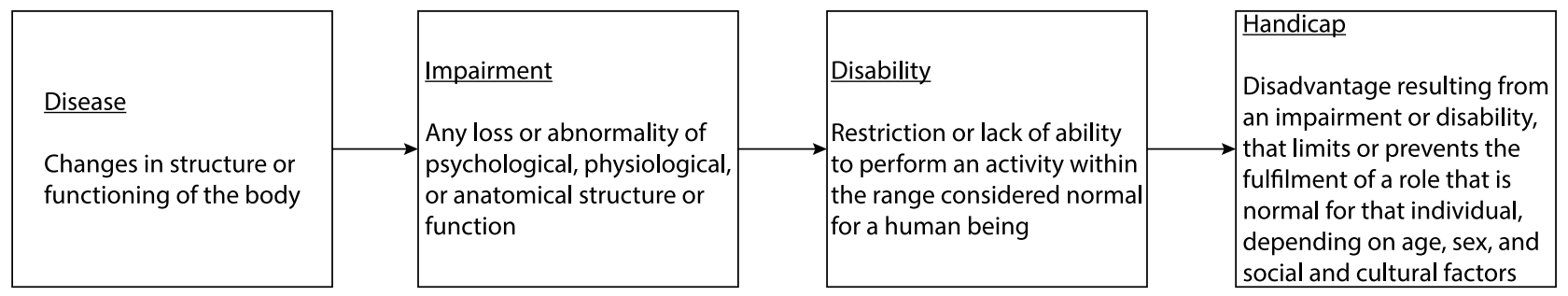

c) WHO's International Classification of Functioning, Disability, and Health (2001)

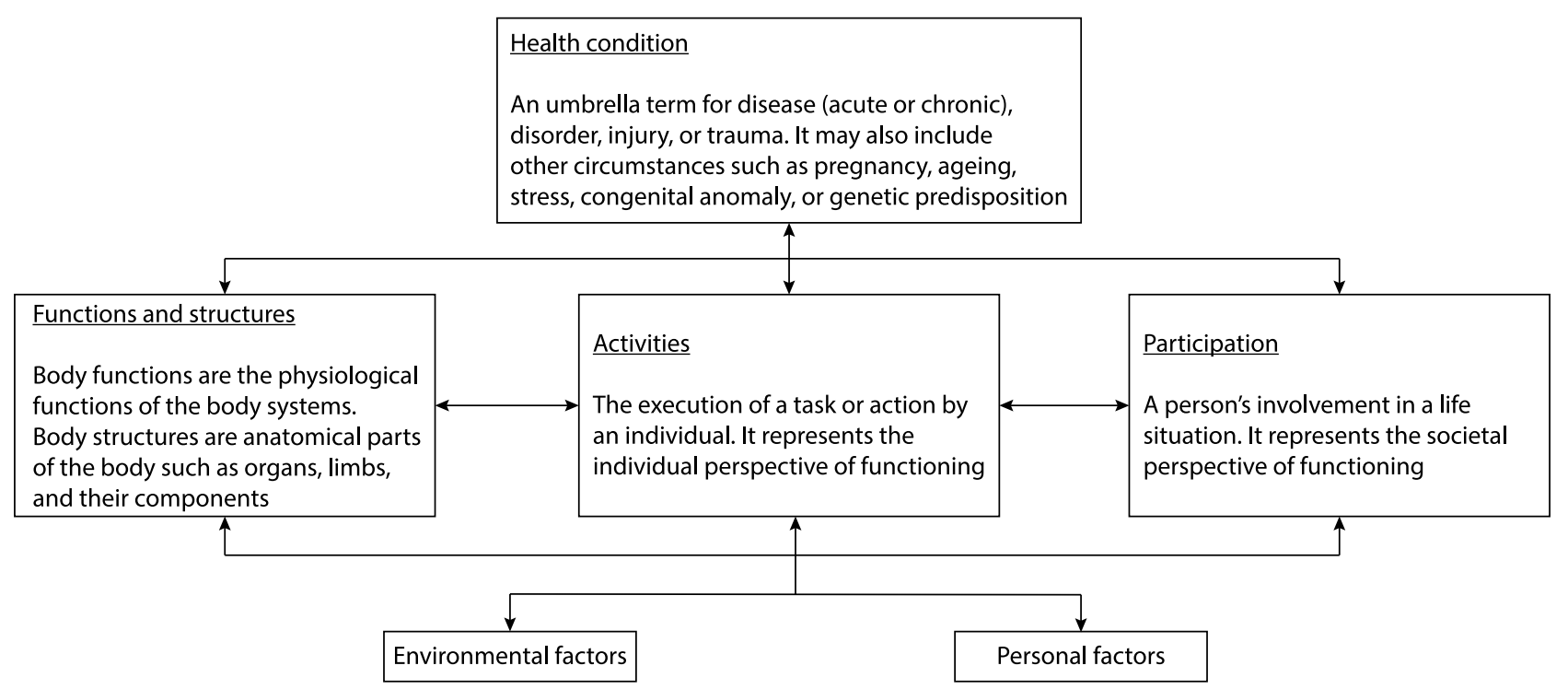

Fig. 2 (a) Graphical representation of Nagi's Disablement Model (Nagi 1965, 1991), (b) the WHO's ICIDH, and (c) the WHO's ICF. Figure 2b and $2 \mathrm{c}$ are adapted with permission from the World Health Organization $(1980,2001)$.

Publisher's Note Springer Nature remains neutral with regard to jurisdictional claims in published maps and institutional affiliations. 